\section{Micropropagation of Japanese Chestnut (Castanea crenata Sieb. et Zucc.) Seedlings}

\author{
Takuya Tetsumura ${ }^{1}$ and Kensuke Yamashita ${ }^{2}$ \\ Department of Plant and Animal Science, Faculty of Agriculture, University of \\ Miyazaki, Miyazaki 889-2192, Japan
}

Additional index words. BW medium, root-developing substrate, shoot multiplication

\begin{abstract}
Japanese chestnut (Castanea crenata Sieb. et Zucc.) was micropropagated from nodal explants of 2-month-old seedlings, and the regenerated plantlets were acclimatized after potting. For in vitro establishment, $5 \mu \mathrm{M}$ zeatin was more effective than $5 \mu \mathrm{M}$ BA or TDZ, and Sato's (BW) medium was as effective as $\mathrm{MS}(1 / 2 \mathrm{NO})$ medium. Driver-Kuniyuki walnut medium produced more shoots showing hyperhydricity symptoms. In the multiplication culture, the higher the concentration of zeatin added to $\mathrm{BW}$ medium, the greater the number of shoots showing hyperhydricity, although the longest shoot was obtained when $6.9 \mu \mathrm{M}$ zeatin was added. After planting in $1 / 2 \mathrm{BW}$ medium with $15 \mu \mathrm{M}$ IBA for $5 \mathrm{~d}$ to induce rooting, shoots planted in $1 / 2 \mathrm{BW}$ medium plus vermiculite gelled with Gellan Gum (SV substrate) rooted better than those in either the gelled medium without vermiculite (S substrate) or vermiculite plus liquid medium ( $V$ substrate). One third of the shoots planted in the $\mathrm{V}$ substrate died, although $62 \%$ of the surviving shoots rooted well. Of the shoots planted in the S substrate, $83 \%$ survived, but only $35 \%$ of these survived rooting. Shoots rooted in the $S V$ and $V$ substrates survived well after the completion of acclimatization, and shoots rooted in the SV substrate grew more vigorously after potting. Chemical names used: 6-benzyladenine (BA); 6-(4-hydroxy-3-methyl-but-2-enylamino)purine (zeatin); indole-3butyric acid (IBA); 1-phenyl-3-(1,2,3-thiadiazol-5-yl)urea (thidiazuron, TDZ).
\end{abstract}

Japanese chestnut (Castanea crenata Sieb. et Zucc.), native to Japan and the KoreanPeninsula, has been cultivated in Japan, Korea, and China. About 26,400 ha of plantings in Japan produced about $26,700 \mathrm{t}$ of nuts in 2000 . The trees of japanese chestnut are more precocious, produce larger nuts, and yield better than other cultivated Castanea species (Kotobuki et al. 1999). However, growers in Japan often encounter the problem of young trees withering and dying, which is mainly caused by fungal black root rot disease (Sugimoto, 1999), freezing injury (Horimoto and Araki, 1999) and graft incompatibility (Torikata and Higuchi, 1962). Production of own-rooted trees and clonal propagation of resistant rootstocks could solve these problems. In practice, however, commercial cultivars in Japan have been propagated by grafting onto their seedling rootstocks, because propagation of japanese chestnut cutting is very difficult (Machida and Fujii, 1969), which is true for other Castanea species.

Micropropagation of Castanea species has been investigated on european chestnut $(C$. sativa) (Rodriguez, 1982; Vieitez and Vieitez, 1980, 1983), chinese chestnut (C. mollissima) (Qi-guang et al., 1986), american chestnut ( $C$.

Received for publication 6 Oct. 2003. Accepted for publication 10 May 2004. We thank Masahiko Shimmomura at Ishikawa Agricultural College for his valuable advice in conducting the experiments, and Munekiyo Horimoto and Kenichi Hamada at Hyogo Prefectural Agricultural Institute for providing japanese chestnut nuts.

${ }^{1}$ Associate professor and corresponding author; e-mail tetsumur@plant.miyazaki-u.ac.jp.

${ }^{2}$ Professor. dentata) (Serres et al., 1990; Xing et al., 1997), and their hybrids (Nas et al., 2003). In most of the reports on in vitro multiplication, tissue culture of Castanea species was successful, but some reports showed that Castanea is still one of the most difficult species to establish in vitro, multiply, and root when explants were obtained from adult trees (Ballester et al., 1989; Piagnani et al., 1996; Sanchez et al., 1997a, 1997b; Soylu and Erturk, 1999). To our knowledge, there have been no reports on either in vitro regeneration or successful acclimatization of japanese chestnut explants, except by Chevre and Salesses (1987), who did not describe their methods in detail. Micropropagation of hybrid clones of $C$. crenata and $C$. sativa, the rootstocks resistant to ink disease, has been intensively studied (Ballester et al., 1989; Miranda and Fernandez, 2001; Sanchez et al., 1997a, 1997b; Vieitez et al., 1983). In our preliminary trials, nodal explants of some commercial cultivars in Japan were not established in vitro, and it was impossible to multiply the shoots by subculturing. Therefore, the objective of this study was to establish a micropropagation system using japanese chestnut seedlings, as a first step to finding a method for cultivar propagation.

\section{Materials and Methods}

In vitro establishment. Stratified nuts of 'Tanzawa' and 'Ginyose' japanese chestnut, provided by the Hyogo Prefectural Agricultural Institute, were planted in pots in a growth chamber at $25^{\circ} \mathrm{C}$ under a $16-\mathrm{h}$ photoperiod with a photon flux of $60 \mu \mathrm{mol} \cdot \mathrm{m}^{-2} \cdot \mathrm{s}^{-1}$ provided by cool-white fluorescent lamps. Softwood shoots were taken from 2-month-old seedlings, and the apices of shoots were discarded. After the leaves were removed, leaving $1 \mathrm{~cm}$ of the petiole base attached to the stem, the shoots were rinsed for 30 min in running tap water, surface-disinfected for $20 \mathrm{~min}$ in $0.5 \%$ sodium hypochlorite solution, containing $0.1 \%$ Tween 20 , and washed three times with sterile water. After cutting into 1-node, 2-cm-long segments, they were placed vertically and singly in test tubes $(2.5 \times$ $12 \mathrm{~cm}$ ) containing $10 \mathrm{~mL}$ of culture medium. The following three basal media were used in combination with three cytokinins (BA, TDZ, or zeatin) at $5 \mu \mathrm{m}$ in the medium: Sato's (BW) medium (Sato, 1991) consisting of half-strength broad-leaved tree (BT) medium (Chalupa, 1984) and half-strength woody plant (WP) medium (Lloyd and McCown, 1981), DriverKuniyuki walnut (DKW) medium (Driver and Kuniyuki, 1984), and Murashige and Skoog's medium (Murashige and Skoog, 1962) with half-strength of nitrates (Vieitez and Vieitez, 1983; Vieitez et al., 1986) [MS( $\left.\left.1 / 2 \mathrm{NO}_{3}\right)\right]$. All of the media contained $0.8 \%(\mathrm{w} / \mathrm{v})$ agar (Wako Pure Chem. Ind., Ltd., Tokyo) and 3\% (w/v) sucrose. The medium $\mathrm{pH}$ was adjusted to 5.5 with $\mathrm{NaOH}$ before autoclaving at $121^{\circ} \mathrm{C}$ and $120 \mathrm{kPa}$ for $15 \mathrm{~min}$. Cultures were maintained at $25^{\circ} \mathrm{C}$ under a $16-\mathrm{h}$ photoperiod with a photon flux of $60 \mu \mathrm{mol} \cdot \mathrm{m}^{-2} \cdot \mathrm{s}^{-1}$ provided by cool-white fluorescent lamps. The surviving explants, number of shoots, length of shoots, number of expanded leaves, and number of shoots showing hyperhydricity symptoms were recorded after 30 $\mathrm{d}$ of culture. The number of explants collected from the young seedlings was $<20 /$ seedling. Hence, each treatment has five explants from five seedlings, i. e., the genotypes of each explant in the treatment were different, and the experiment was conducted twice.

Multiplication. BW medium supplemented with $5 \mu \mathrm{M}$ zeatin, which showed the best results in the establishment phase, was used for subsequent subcultures. After subculturing at 1-month intervals for half a year, the elongating shoots were cut into 1-node segments each with a leaf and placed singly and vertically in the same test tubes as used in the establishment phase, containing BW medium supplemented with $0.2,1,5$, or $25 \mu \mathrm{M}$ zeatin. The culture conditions were the same as those of the establishment phase. The surviving shoots, number of shoots, length of shoots, number of shoots showing hyperhydricity symptoms, and the multiplication rate were recorded after $30 \mathrm{~d}$ of culture. The multiplication rate was calculated from the number of 1-node segments harvested from healthy shoots developing from a cultured segment. For each treatment, 8 to 10 shoots of each clone of four seedlings were used, and the experiment was conducted twice.

Root induction and root development. BW medium supplemented with $1 \mu \mathrm{M}$ zeatin, which showed the best results in the multiplication phase, was used for subsequent subcultures. After subculturing for a year, the shoots, $\approx 2$ $\mathrm{cm}$ long, were cultured in half-strength BW $(1 / 2 \mathrm{BW})$ medium supplemented with $15 \mu \mathrm{M}$ IBA for $5 \mathrm{~d}$ in dark to induce rooting. Three shoots were placed in a $100-\mathrm{mL}$ Erlenmeyer flask containing $20 \mathrm{~mL}$ medium. After the root induction treatment, the shoots were transferred 
to the following three kinds of root-developing substrate with 3\% sucrose but without growth regulators: $1 / 2 \mathrm{BW}$ medium gelled with $0.2 \%$ (w/v) Gellan Gum (Wako Pure Chem. Ind., Ltd., Tokyo) (S substrate), 1/2 BW medium plus fine vermiculite (Asahi-Kogyo Inc., Okayama, Japan) gelled with Gellan Gum (SV substrate), which was prepared by pouring $40 \mathrm{~mL}$ of hot liquid medium containing $0.2 \%$ Gellan Guminto a $100 \mathrm{~mL}$ erlenmeyer flask with $50 \mathrm{~mL}$ of fine vermiculite following the procedure of Jay-Allemand et al (1992), and $1 / 2$ BW liquid medium plus vermiculite (4:5, v/v) (V substrate). Three shoots were placed in a 100-mLerlenmeyerflask containing the medium. After $30 \mathrm{~d}$ in culture for root development, the surviving shoots were carefully removed from the substrate and rinsed in distilled water for $5 \mathrm{~s}$. The number of surviving shoots, number of rooted shoots, number of primary roots, and length of the longest roots were recorded. The culture conditions were the same as those of the establishment phase, except for dark incubation for root induction. For each treatment, 12 to 18 shoots of each clone of six seedlings were used, and the experiment was conducted twice.

Acclimatization. The rooted shoots were planted singly in $57 \times 57$-mm Jiffy pots (Jiffy Products, Batavia, Ill.) filled with fine vermiculite saturated with $1 / 2 \mathrm{BW}$ liquid salts without sucrose, in $75 \times 100-\mathrm{mm}$ polycarbonate vessels and covers (Asahi techno glass corp., Tokyo) that

Table 1. Effects of basal medium and cytokinin on survival, length of shoots, number of expanded leaves, and number of shoots showing hyperhydricity in explants from 2-month-old japanese chestnut seedlings, $30 \mathrm{~d}$ after in vitro culture.

\begin{tabular}{|c|c|c|c|c|c|}
\hline Treatment & $\begin{array}{c}\text { Survival } \\
(\%)\end{array}$ & $\begin{array}{l}\text { No. of } \\
\text { shoots }\end{array}$ & $\begin{array}{c}\text { Length of } \\
\text { shoots }(\mathrm{mm})\end{array}$ & $\begin{array}{l}\text { No. of } \\
\text { leaves }\end{array}$ & $\begin{array}{c}\text { Hyperhydric } \\
\text { shoots }(\%)\end{array}$ \\
\hline \multicolumn{6}{|l|}{ Basal medium } \\
\hline $\mathrm{BW}^{\mathrm{z}}$ & $68 a^{y}$ & $1.2 \mathrm{a}$ & $17.7 \mathrm{a}$ & $3.0 \mathrm{a}$ & $50 \mathrm{~b}$ \\
\hline $\mathrm{DKW}^{\mathrm{x}}$ & $70 \mathrm{a}$ & $1.3 \mathrm{a}$ & $16.8 \mathrm{a}$ & $2.9 \mathrm{a}$ & $77 \mathrm{a}$ \\
\hline $\operatorname{MS}\left(1 / 2 \mathrm{NO}_{3}\right)^{\mathrm{w}}$ & $56 a$ & $1.2 \mathrm{a}$ & $18.2 \mathrm{a}$ & $2.7 \mathrm{a}$ & $47 \mathrm{~b}$ \\
\hline \multicolumn{6}{|l|}{ Cytokinin $(5 \mu \mathrm{M})$} \\
\hline $\mathrm{BA}$ & $61 \mathrm{~b}$ & $1.2 \mathrm{~b}$ & $16.5 \mathrm{~b}$ & $2.0 \mathrm{~b}$ & $67 \mathrm{a}$ \\
\hline TDZ & $49 \mathrm{~b}$ & $1.0 \mathrm{~b}$ & $9.6 \mathrm{c}$ & $1.2 \mathrm{c}$ & $39 \mathrm{~b}$ \\
\hline Zeatin & $85 \mathrm{a}$ & $1.5 \mathrm{a}$ & $26.6 \mathrm{a}$ & $5.4 \mathrm{a}$ & $69 \mathrm{a}$ \\
\hline \multicolumn{6}{|l|}{ Significance } \\
\hline Basal medium & NS & NS & NS & NS & $*$ \\
\hline Cytokinin & $* *$ & $*$ & $* *$ & $* *$ & $*$ \\
\hline Interaction & NS & NS & NS & NS & NS \\
\hline
\end{tabular}

zSato's medium (Sato, 1991) consisting of half-strength broad-leaved tree (BT) medium (Chalupa, 1984) and half-strength woody plant (WP) medium (Lloyd and McCown, 1981).

${ }^{\mathrm{y}}$ Means in the same column within the same factor followed by the same letter are not significantly different according to Fisher's protected least significant difference at $P \leq 0.05$.

${ }^{x}$ Driver-Kuniyuki walnut medium (Driver and Kuniyuki, 1984)

"Murashige and Skoog's medium (Murashige and Skoog, 1962) with half-strength of nitrates (Vieitez and Vieitez, 1983; Vieitez et al., 1986).

NS,*,**Nonsignificant or significant at $P \leq 0.05$ or 0.01 , respectively.

Table 2. Effect of substrate for rooting on survival, rooting, number of roots per rooted shoot, and length of longest roots in shoots established from nodal explants taken from 2-month-old japanese chestnut seedlings after $30 \mathrm{~d}$ in culture. Shoots cultured in root induction medium for $5 \mathrm{~d}$ before rooting were used.

\begin{tabular}{|c|c|c|c|c|c|}
\hline \multirow[b]{2}{*}{ Substrate $^{y}$} & \multirow{2}{*}{$\begin{array}{c}\text { Survival } \\
(\%)\end{array}$} & \multicolumn{2}{|c|}{ Rooting $^{2}(\%)$} & \multirow{2}{*}{$\begin{array}{l}\text { No. of roots/ } \\
\text { rooted shoot }\end{array}$} & \multirow{2}{*}{$\begin{array}{c}\text { Length of } \\
\text { longest } \\
\text { root }(\mathrm{mm})\end{array}$} \\
\hline & & Original & SurvP & & \\
\hline$\overline{\text { Gellan Gum (S) }}$ & $83 \mathrm{a}^{\mathrm{x}}$ & $29 \mathrm{~b}$ & $35 \mathrm{c}$ & $2.0 \mathrm{~b}$ & $12 \mathrm{~b}$ \\
\hline Vermiculite + liquid (V) & $66 \mathrm{~b}$ & $42 \mathrm{~b}$ & $62 \mathrm{~b}$ & $3.5 \mathrm{a}$ & $31 \mathrm{a}$ \\
\hline Gellan Gum + vermiculite (SV) & $86 \mathrm{a}$ & $67 \mathrm{a}$ & $83 \mathrm{a}$ & $3.8 \mathrm{a}$ & $33 \mathrm{a}$ \\
\hline
\end{tabular}

${ }^{\mathrm{z}}$ Rooting $(\%)$ original $=$ number of rooted shoots as a percentage to the original number; rooting $(\%)$ SurvP = number of rooted shoots as a percentage to those surviving at the end of the culture. See Wilson and Struve (2003).

${ }^{y}$ All substrates were saturated with $1 / 2 \mathrm{BW}$ medium without growth regulators.

'Means in the same column followed by the same letter are not significantly different according to Fisher's protected least significant difference at $P \leq 0.05$.

Table 3. Effect of substrate for rooting on acclimatization survival, plant height, and number of leaves of plantlets regenerated from nodal explants taken from 2-month-old japanese chestnut seedlings $30 \mathrm{~d}$ after potting.

\begin{tabular}{|c|c|c|c|c|}
\hline \multirow[b]{2}{*}{ Substrate } & \multicolumn{2}{|c|}{ Acclimatization survival $^{\mathrm{z}}(\%)$} & \multirow{2}{*}{$\begin{array}{c}\text { Plant ht } \\
\text { (mm) }\end{array}$} & \multirow{2}{*}{$\begin{array}{l}\text { No. of } \\
\text { leaves }\end{array}$} \\
\hline & Rooted shoots & Original shoots & & \\
\hline$\overline{\text { Gellan Gum}^{y}(\mathrm{~S})}$ & $63 b^{x}$ & $18 \mathrm{c}$ & $52 \mathrm{~b}$ & $6.7 \mathrm{~b}$ \\
\hline Vermiculite + liquid ${ }^{\mathrm{y}}(\mathrm{V})$ & $85 \mathrm{a}$ & $38 \mathrm{~b}$ & $58 \mathrm{~b}$ & $6.2 \mathrm{~b}$ \\
\hline Gellan Gum + vermiculite ${ }^{\mathrm{y}}(\mathrm{SV})$ & $78 \mathrm{ab}$ & $56 \mathrm{a}$ & $86 a$ & $9.0 \mathrm{a}$ \\
\hline
\end{tabular}

${ }^{\mathrm{z}}$ Acclimatization survival $(\%)$ rooted shoots $=$ the number of survival as a percentage to those of rooted shoots; acclimatization survival $(\%)$ original shoots $=$ the number of survival as a percentage to that of shoots precultured in the root induction medium.

${ }^{y}$ All substrates were saturated with $1 / 2 \mathrm{BW}$ medium without growth regulators.

${ }^{x}$ Means in the same column followed by the same letter are not significantly different according to Fisher's protected least significant difference at $P \leq 0.05$.

were autoclaved. The culture conditions were the same as those of the establishment phase, except for continuous lighting to promote growth of the rooted shoots. Between 10 and $25 \mathrm{~d}$ after planting, the cover was gradually removed from the vessel. The number of surviving plants, plant height, and number of leaves were recorded $30 \mathrm{~d}$ after potting. Since the acclimatization test was conducted after rooting, the number of rooted shoots used for each treatment ranged from 2 to 12 depending on the percentages of rooting and the experiment was conducted twice.

Statistical analysis. All data were subjected to analysis of variance (ANOVA), and percentage of data was subjected to arcsin transformation before ANOVA. The data in the establishment test were subjected to three-way ANOVA with basal media, cytokinins and nut cultivars. However, there was no significant difference between the nut cultivars and were no significant interactions between the nut cultivar and the other treatments, so that the data were subjected to two-way ANOVA with basal media and cytokinins. The data in the multiplication test were subjected to two-way ANOVA with concentrations of zeatin and clones, and also subjected to regression analysis.

\section{Results and Discussion}

Invitroestablishment. Among the three kinds of cytokinin tested, zeatin gave the best results in all investigations, except for the percentage of shoots showing hyperhydricity symptoms (Table 1). Therefore, we used zeatin for shoot multiplication. In other Castanea species, zeatin induced more vigorous shoots than BA, but did not promote the multiplication of axillary shoots (Qi-guang et al., 1986; Vieitez and Vieitez, 1980). In this study, however, zeatin produced more shoots than BA, which was usually used for the shoot multiplication of american and european chestnuts (Rodriguez, 1982; Vieitez and Vieitez, 1983; Vieitez et al., 1986; Xing et al., 1997). TDZ was less effective than the other cytokinins, although it induced multiple shoots on the cotyledonary nodes of $C$. sativa (San-Jose et al., 2001).

The kind of basal medium did not affect most results significantly, although more than three-quarters of the shoots established on DKW medium, which has been used for subculturing shoots of C. sativa (Rugini et al., 1993), showed hyperhydricity symptoms (Table 1 ). When the chestnut clones were multiplied in vitro, the genotype influence was an important factor (Miranda and Fernandez, 2001). The difference in genotype of each explant in each treatment in the establishment test might reduce the effects of the basal medium, although the means and the interactions of the results did not vary with the nut parents. The reason we used BW medium for shoot multiplication was that all of the explants cultured on BW medium supplemented with zeatin survived. BW medium was effective in avoiding necrosis of in vitro shoots of Quercus acutissima (Sato, 1991), the same Fagaceae family as chestnut. $\mathrm{MS}\left(1 / 2 \mathrm{NO}_{3}\right)$ medium was generally used for chestnut micropropagation (Miranda and Fernandez, 2001; Soylu and Erturk, 1999; Vieitez and Vieitez, 1983; Vieitez et 
al., 1983) and was as effective as BW medium for the establishment of explants of japanese chestnut, but $15 \%$ of the explants cultured on $\mathrm{MS}\left(1 / 2 \mathrm{NO}_{3}\right)$ medium supplemented with zeatin died. The kind of basal medium was an important factor in causing the chlorosis of in vitro chestnut shoots (Miranda and Fernandez, 2001).
Multiplication. According to ANOVA, the means and the interactions of the results did not vary with the clone. Therefore, the data were analyzed for the concentration of zeatin. There were significant effects $(P \leq 0.05)$ of the concentration on the percentage of surviving shoots, length of shoots, and percentage

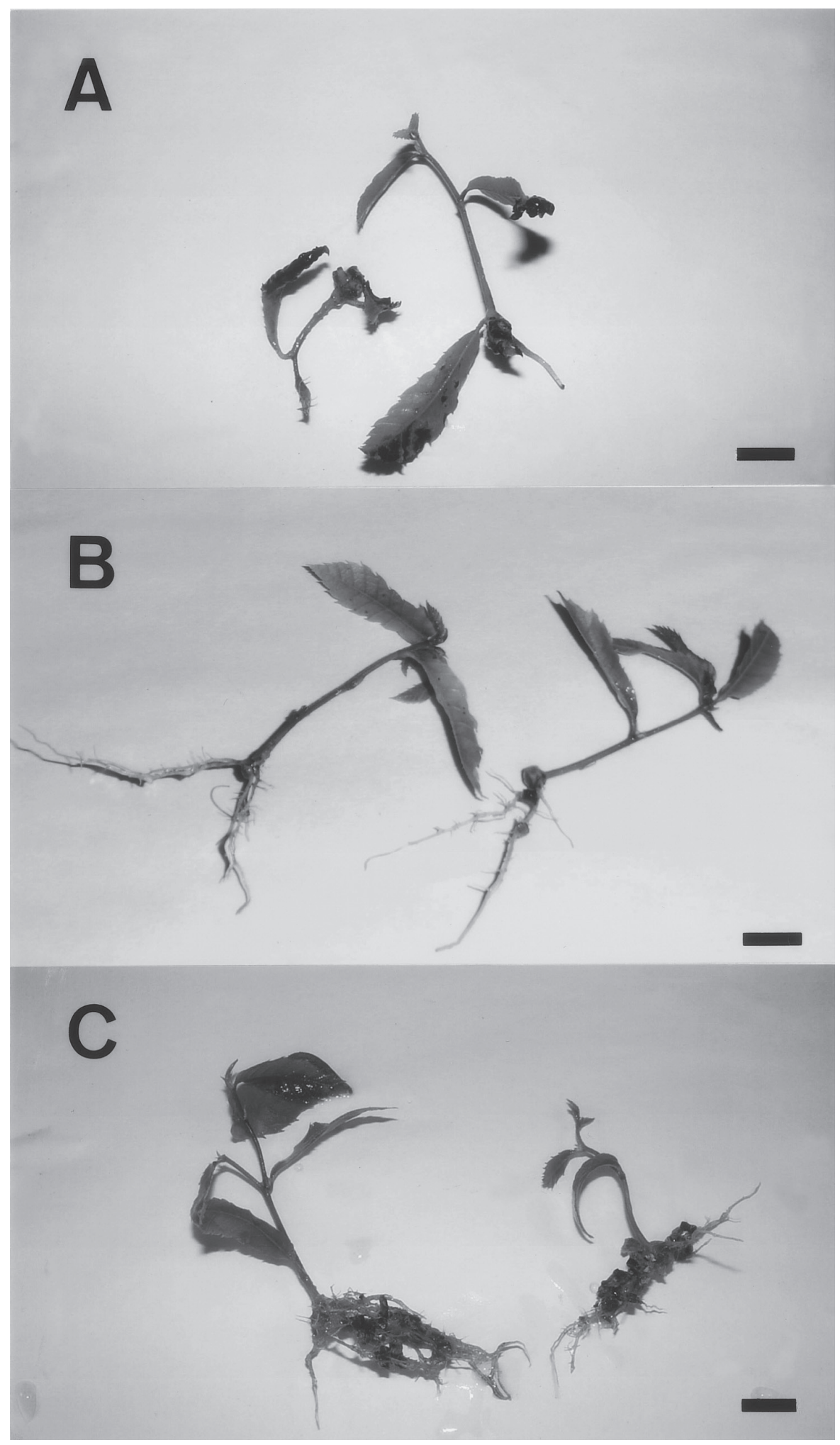

Fig. 1. Roots of shoots established from nodal explants taken from 2-month-old japanese chestnut seedlings, developing after $30 \mathrm{~d}$ in culture (A) in $1 / 2 \mathrm{BW}$ medium gelled with Gellan Gum (S substrate); (B) in 1/2 BW liquid medium plus vermiculite (V substrate); (C) in $1 / 2 \mathrm{BW}$ medium plus vermiculite gelled with Gellan Gum (SV substrate). All scale bars $=1 \mathrm{~cm}$.

of shoots showing hyperhydricity symptoms, which increased with increasing concentration of zeatin $[\mathrm{y}(\%)=51.3+9.63 \ln (\mathrm{x})$ (concentration), $\left.P \leq 0.01, r^{2}=0.363\right]$. The multiplication rate decreased as the concentration increased [y $(\%)=156-20.1 \ln (\mathrm{x})$ (concentration), $P$ $\leq 0.05, r^{2}=0.1243$, although the significant regression equation between the concentration and the length of shoots $[\mathrm{y}(\mathrm{mm})=17.7+$ $0.231 \mathrm{x}-0.0168 \mathrm{x}^{2}$ (concentration), $P \leq 0.01, r^{2}$ $=0.225]$ predicted that the longest shoot would be obtained when zeatin was supplemented at $6.9 \mu$ m. The percentage of survival increased with the increase of zeatin concentration [y $(\%)=84.0+3.34 \ln (\mathrm{x})$ (concentration), $P \leq$ $\left.0.05, r^{2}=0.176\right]$. For subsequent subcultures, we used BW medium supplemented with $1 \mu \mathrm{M}$ zeatin, on which half of the shoots did not show hyperhydricity. In vitro Castanea shoots were generally subcultured with 0.44-2.22 $\mu \mathrm{M}$ BA (Miranda and Fernandez, 2001; Qi-guang et al., 1986; Rodriguez, 1982; Sanchez et al., 1997a, 1997b; Vieitez and Vieitez, 1983; Xing et al., 1997). Multiple shoots were seldom produced from the 1-node segments on the treatment medium used in this study.

Root induction and root development. The addition of vermiculite to the solidified substrate for root development improved the rooting of shoots cultured on the medium for root induction (Table 2). Shoots planted in the SV substrate rooted better than those planted in the S substrate, and the former was superior to the latter in the number of roots and the length of the longest roots produced, as has been previously reported in walnut (Jay-Allemand et al., 1992). Jay-Allemand et al. (1992) presumed that the vermiculite mixed with Gellan Gum in the right proportion gave a good balance between aeration and the availability of water at the bottom of the shoot, and promoted root initiation and development. The shoots rooted well in the SV substrate, partly because we used juvenile materials the same as Qi-guang et al. (1986) did. However, for rooting the shoots from adult materials, the rooting procedure such as IBA concentration and basal medium concentration must be improved as Serres et al. (1990) tried on american chestnut microcuttings.

One third of the shoots planted in the V substrate died during culture for root development, although $62 \%$ of the surviving shoots rooted well (Table 2). On the other hand, $83 \%$ of the shoots planted in the $\mathrm{S}$ substrate survived, but only $35 \%$ of the surviving shoots rooted. The kind of substrate used for root development affected the rooting of chestnut shoots (Sanchez et al., 1997b) or did not (Goncalves et al., 1998). Such an inconsistency might be a result of difference in survival of shoots during culture for root development. We showed that the $\mathrm{S}$ substrate gave better survival of shoots than the $\mathrm{V}$ substrate, but performed worse in rooting, which was improved by the addition of vermiculite. The percentages of survival and rooting showed significant differences $(P \leq$ 0.05 ) between the clones, although there were no significant interactions between the clone and substrate.

Acclimatization. Shoots rooted in the SV and $\mathrm{V}$ substrate survived well after acclima- 
tization (Table 3), probably as a result of a well-developed root system (Fig. 1, Table 2). More than one-half of the shoots planted in the SV substrate developed into plantlets after completion of acclimatization, while only $18 \%$ of those in the S substrate and $38 \%$ of those in the $\mathrm{V}$ substrate developed into plants (Table $3)$. The acclimatization survival and growth showed significant differences $(P \leq 0.05)$ among the clones, although there were no significant interactions in any investigation items between the clone and substrate.

Shoots rooted in the SV substrate grew better after potting than those rooted in the $\mathrm{S}$ or $\mathrm{V}$ substrate (Table 3 ). Necrosis of chestnut shoottips during rooting has often been observed (Vieitez et al., 1989; Xing et al., 1997). In this study necrosis was also observed, irrespective of the type of substrate in the medium for root development. However, most of the shoots that rooted in the SV substrate did not show shoottip necrosis, produced new shoots during root development culture, and continued growing after potting, possibly because of good aeration of the roots (Jay-Allemand et al., 1992). Most of the shoots rooted in the $\mathrm{V}$ substrate, in which one-third of the shoots did not survive, dropped their older leaves during root developing culture, even though they produced new shoots. Because of the partially inhibited growth, they grew slowly after potting. Few of the shoots rooted in the $\mathrm{S}$ substrate produced new shoots during the root development culture and grew vigorously after potting, but once surviving ex vitro, all were successfully transplanted to the field like other shoots rooted in the V and SV substrate. All the micropropagated trees have grown well for 2 years.

We have demonstrated micropropagation and acclimatization of plantlets obtained from japanese chestnut seedlings. We tried to apply this procedure to explants taken from adult trees of japanese chestnut cultivars, but it was found out that further improvement of the multiplication culture is necessary.

\section{Literature Cited}

Ballester, A., M.C. Sanchez, and A.M. Vieitez. 1989. Etiolation as a pretreatment for in vitro establishment and multiplication of mature chestnut. Physiol. Plant. 77:395-400.

Chalupa, V. 1984. In vitro propagation of oak (Quercus robur L.) and linden (Tilia cordata Mill.) . Biologia Plant. (Praha) 26:374-377.

Chevre, A-M. and G. Salesses. 1987. Choice of explants for chestnut micropropagation. Acta Hort. 212:517-523.

Driver, J.A. and A.H. Kuniyuki. 1984. In vitro propagation of Paradox walnut rootstock. HortScience 19:507-509.

Goncalves, J.C., G. Diogo, and S. Amancio. 1998. In vitro propagation of chestnut (Castanea sativa $x$ C. crenata): Effects of rooting treatments on plant survival, peroxidase activity and anatomical changes during adventitious root formation. Scientia Hort. 72:265-275.

Horimoto, M. and H. Araki. 1999. Effect of restricted water uptake on freezing injury of japanese chestnut (Castanea crenata Sieb. et Zucc.) trees (in Japanese with English summary). J. Agr. Meteorol. 55:329-336.

Jay-Allemand C., P. Capelli, and D. Cornu. 1992. Root development of in vitro hybrid walnut microcuttings in a vermiculite-containing gelrite medium. Scientia Hort. 51:335-342.

Kotobuki, K., T. Saito, Y. Kashimura, and M. Shoda. 1999. Chestnut breeding program in national institute of fruit tree science, Japan. Acta Hort. 494:323-326.

Lloyd, G. and B. McCown. 1981. Commerciallyfeasible micropropagation of mountain laurel, Kalmia latifolia, by use of shoot-tip culture. Combined Proc. Intl. Plant Propagators' Soc. 30:421-427.

Machida, H. and T. Fujii. 1969. Studies on the promotion of the rooting in cuttings and the formation of adventitious roots (In Japanese with English summary). Mem. Fac. Agr. Tokyo Univ. Educ. 15:48-92.

Miranda, M.E. and J. Fernandez. 2001. Genotypic and environmental variation of Castanea crenata $\times$ C. sativa and Castanea sativa clones in aptitude to micropropagation. Silvae Genet. 50:153-162.

Murashige, T. andF. Skoog. 1962. A revised medium for rapid growth and bioassays with tobacco tissue cultures. Physiol. Plant. 15:473-497.

Nas M.N., P.E. Read, and V. Miller. 2003. In vitro "rejuvenation" of woody species is temporary. Acta Hort. 625:211-215.

Piagnani, C., G. Zocchi, and I. Mignani. 1996. Influence of $\mathrm{Ca}^{2+}$ and 6-benzyladenine on chestnut (Castanea sativa Mill.) in vitro shoot-tip necrosis. Plant Sci. 118:89-95.

Qi-guang, Y., P.E. Read, C.D. Fellman, and M.A. Hosier. 1986. Effect of cytokinin, IBA, and rooting regime on chinese chestnut cultured in vitro. HortScience 21:133-134.

Rodriguez, R. 1982. Multiple shoot-bud formation and plantlet regeneration on Castanea sativa Mill. seeds in culture. Plant Cell Rpt. $1: 161-164$

Rugini, E., A. Jacoboni, and M. Luppino. 1993. Role of basal shoot darkening and exogenous putrescine treatments on in vitro rooting and on endogenous polyamine changes in difficult-to- root woody species. Scientia Hort. 53:63-72.

Sanchez, M.C., A. Ballester, and A.M. Vieitez. 1997a. Reinvigoration treatments for the micropropagation of mature chestnut trees. Ann. Sci. For. 54:359-370.

Sanchez, M.C., M.C. San-Jose, E. Ferro, A. Ballester, and A.M. Vieitez. 1997b. Improving micropropagation conditions for adult-phase shoots of chestnut. J. Hort. Sci. 72:433-443.

San-Jose, M.C., A. Ballester, and A.M. Vieitez. 2001. Effect of thidiazuron on multiple shoot induction and plant regeneration from cotyledonary nodes of chestnut. J. Hort. Sci. Biotechnol. 76:588-595.

Sato, T. 1991. Basic studies of organ and callus culture in woody plants (In Japanese with English summary). Bul. For. Forest Prod. Res. Inst. 360:35-119.

Serres, R., P. Read, W. Hackett, and P. Nissen. 1990. Rooting of american chestnut microcuttings. J. Environ. Hort. 8:86-88.

Soylu, A. and U. Erturk. 1999. Researches on micropropagation of chestnut. Acta Hort. 494:247-253.

Sugimoto, A. 1999. The effect of different rootstocks on the occurrence of black root rot (Macrophoma castaneicola and Didymosporium radicicola) of chestnut (Castanea crenata Sieb. et. Zucc.) trees (in Japanese with English summary). J. Jpn. Soc. Hort. Sci. 68:349-354.

Torikata, H. and H. Higuchi. 1962. Studies on the grafting congeniality in chestnut trees. I. Influence of rootstocks on the growth and mineral composition (in Japanese with English summary). J. Jpn. Soc. Hort. Sci. 31:115-122.

Vieitez, A.M. and M.L. Vieitez. 1980. Culture of chestnut shoots from buds in vitro. J. Hort. Sci. 55:83-84.

Vieitez, A.M. and M.L. Vieitez. 1983. Castanea sativa plantlets proliferated from axillary buds cultivated in vitro. Scientia Hort. 18:343-351.

Vieitez, A.M., A. Ballester, M.L. Vieitez, and E. Vieitez. 1983. In vitro plantlet regeneration of mature chestnut. J. Hort. Sci. 58:457-463.

Vieitez, A.M., M.L. Vieitez, and E. Vieitez. 1986. Chestnut (Castanea spp.), p. 393-414. In: Y.P.S. Bajaj (ed.). Biotechnology in agriculture and forestry. vol. 1. Trees I. Springer-Verlag, Berlin.

Vieitez, A.M., C. Sanchez, and C. San-Jose. 1989. Prevention of shoot-tip necrosis in shoot cultures of chestnut and oak. Scientia Hort. 41:151-159.

Wilson, P.J. and D.K. Struve. 2003. Rooting variables for stem cuttings. J. Hort. Sci. Biotechnol. 78:29-31.

Xing, Z., M.F. Satchwell, W.A. Powell, and C.A. Maynard. 1997. Micropropagation of american chestnut: Increasing rooting rate and preventing shoot-tip necrosis. In Vitro Cell Dev. Biol. 33P:43-48. 